\title{
Coordination through Integration
}

A critical review on the spatial policy and spatial planning system of France

\author{
Jian $\mathrm{Liu}^{1 *}$ \\ 1 School of Architecture, Tsinghua University \\ * Corresponding Author, Email: liujian@tsinghua.edu.cn
}

Received: Dec 1, 2017; Accepted: May 08, 2018

Key words: Spatial Planning System, Spatial Policy, Coordination, Integration, France

Abstract: In this template file as introduction for the format of this journal. As a country with a long history of spatial development, France is distinguished in the world by its profound tradition of spatial planning. Since the mid-20th century, a multi-dimensional spatial policy framework and a multi-layered spatial planning system have been established and developed successively, for the purpose of guiding comprehensive and well-balanced spatial development all over the country. They help promote balanced regional development and urban-rural development, implement special management over specific areas, and encourage the cooperation of governments and departments at various levels. As a critical review on the spatial policy framework and the spatial planning system of France which have been in force since the 2000s, this paper analyses in a systematic way the structure of the policy framework and the planning system respectively, as well as the interrelation between spatial policies with spatial plans, elaborates the hidden logic of coordination through an integrated spatial planning system for the purpose of a well-balanced spatial development all over the country, and summarizes some key facts that guarantee the efficiency of coordination through integration, such as cooperation among governments and departments, presenting integration in urban plans, and the active role of central government. It concludes that the French experience of coordinating various spatial plans formulated by different stakeholders at different levels through an integral spatial planning system based on an integral spatial policy framework can serve as inspiring reference for developing countries like China that are facing the urgency of structuring an integral spatial planning system to deal with the disconnection or even conflict among different departmental plans concerning spatial development.

\section{INTRODUCTION}

Up to now in China, since its reforms and opening-up in the 1980s, there has been the co-existence of multiple spatial planning systems, including but not limited to Five-Year Socio-Economic Development Planning, UrbanRural Planning, Land Use Planning, and Environmental Protection Planning. They are under the jurisdiction of different governmental departments and intervene in the country's spatial development simultaneously from different perspectives. However, due to the lack of efficient coordination resulting 
from departmental independence, there is often the problem of disconnection or even conflict among them, which leads to not only unnecessary confusions but also low efficiencies in practice. When this problem, as well as its consequences, becomes more and more significant along with the acceleration of China's urbanization, efforts are made by different parties in different ways to promote the coordination of various spatial planning systems, such as the institutional reform of governmental departments, the technical innovation of planning practices, and the theoretical exploration of the planning profession (Huang, 2012; Lai et al., 2013; Luo \& Mao, 2015). Amid this process, more focus is paid to structuring an integral spatial planning system (Xie \& Wang, 2015; Zhu, Deng, \& Pan, 2015), with regard to which the experience of developed countries are often taken as reference, such as that of the Netherlands ( $\underline{S}$. Zhang, Feng, \& Liu, 2014; J. Zhou, Hu, \& Gu, 2017), Germany (Z. Zhang \& Huang, 2007; Y. Zhou, Pu, \& Zhang, 2006), the UK (Yang, 2016; S. Zhou, Zhai, \& Shi, 2017), France (Liu, 2011; Zhuo \& Liu, 2004), and so on.

As a country with a long history of spatial development, France is distinguished in the world by its profound tradition of spatial planning. Since the 20th century, particularly after the Second World War, a multidimensional spatial policy framework and a multi-layered spatial planning system have been established and developed successively, for the purpose of achieving comprehensive and well-balanced spatial development all over the country (Bertrand, 2005; Ecrement, 2002; Gambino, 2010; Geppert, 2015; Ministère des Affaires étrangères, 2006). They help promote balanced regional development and urban-rural development, implement special management over specific areas, and encourage the cooperation of the governments and departments at different levels. The French experience of coordinating various spatial plans formulated by different stakeholders at different levels through an integral spatial planning system based on an integral spatial policy framework can serve as valuable reference for developing countries like China that are facing the urgency of structuring a spatial planning system to deal with the disconnection or even conflict among various departmental plans concerning spatial development.This paper is a critical review on the spatial policy framework and the spatial planning system of France which have been in force since the 2000s, with specific concern regarding coordination and integration to guarantee wellbalanced nationwide spatial development. It analyses in a systematic way the structure of the policy framework and the planning system respectively, as well as the interrelation between spatial policies and spatial plans, elaborates the hidden logic of coordination through an integrated spatial planning system for the purpose of a well-balanced spatial development, and summarizes some key facts that guarantee the efficiency of coordination through integration, such as cooperation among governments and departments, presenting integration in urban plans, and the active role of central government. It concludes that the French experience of coordinating various spatial plans formulated by different stakeholders at different levels through an integral spatial planning system based on an integral spatial policy framework can serve as a model for developing countries like China to structure an integral spatial planning system to face the need of coordination. 


\section{RESEARCH APPROACH}

In France, spatial development and planning refers to the action and practice of distributing the population and their activities, as well as the facilities and communication modes they might use, on the territory of the country in a prospective vision, while taking into account the constrains of nature, humans, economy and strategy (Merlin \& Choay, 1988). As guidance to achieving a comprehensive and well-balanced spatial development in the country, the French spatial policy framework and spatial planning system cover all the national territory, concern all the territorial levels, and involve all the aspects of socio-economic development. At the turn of the new millennium, in response to the new challenges of sustainable development, economic globalization and European unification, and under the circumstance of administrative decentralization, which tends to transfer some decision-making and administrative powers of the State to local territories, including those of spatial planning, according to the Defferre Act of 7 January 1983 relative to competence distribution, remarkable amendments were made with the French spatial policy framework and spatial planning system, according to the Pasqua Act of 4 February 1995 (LOADT) and the Voynet Act of 25 June 1999 (LOADDT), two important acts relative to spatial development and planning. In spite of that, the goal, the structure and the characters of the French spatial policy framework and spatial planning system never change.

Based on mainly literature work, this paper tries to elaborate the hidden logic of coordination through integration for the purpose of promoting wellbalanced spatial development in France. In the following sections, it firstly outlines the French spatial policy framework by clarifying its compositional structure, application scope, and expression form and commenting the specific policies of each category from the aspects of objectivity and responsibility. It then reviews the multi-levelled French spatial planning system, from macro to micro, as concrete expression of the spatial policies, in terms of mission, coverage, contents, and responsibility, as well as the interrelationship between various plans. It goes further to articulate the implementation of the above mentioned spatial policies and spatial plans within the structure of the French administration system, highlighting the mechanism of collaboration and cooperation, based on different kinds of contracts, among the governments and their departments of different levels. Finally, it summarizes the key elements of the successful French experience of coordinating various spatial plans formulated by different stakeholders at different levels through an integral spatial planning system based on an integral spatial policy framework.

\section{SPATIAL POLICY FRAMEWORK OF FRANCE}

The current French spatial policy framework is composed of three kinds of policies, i.e. comprehensive policy, special policy and sectoral policy, with the latter two being the complement and extension of the former one. Aimed at guaranteeing the sustainable development of the country and the common interests of the society, they function together to guide the actions or practices of spatial development that take place all over the country or in certain areas of the country, involving all the territorial levels of State, Region, Department, Commune, and Inter-Communality and concerning all the socio-economic aspects of economy, housing, transportation, culture, 
education, and so on (Table 1). According to the Constitution Amendment Act of 2003, there are three kinds of local territories in France, i.e. Region, Department and Commune. This administrative division system is characterized by a large number of small Communes, without distinction among cities, towns and villages. Due to the large number of small Communes, the Inter-Communal administration system has been in a developed state for a long time, in order to facilitate administration and governance. In reality, there are several kinds of Inter-Communal Associations, such as the Public Agency of Inter-Communal Cooperation (EPCI). Currently in France, there are 18 Regions, 101 Departments, and 36,658 Communes, plus 9,711 EPCIs and about 2,800 other kinds of InterCommunal Associations. Moreover, for the purpose of promoting and coordinating regional development that crosses administrative boundaries, there are more and more Inter-Regional and Inter-Departmental Associations in France.

From the 2000s, the French spatial policies were mainly oriented to strengthening the attractiveness and competitiveness of the national economy by fostering the growth of new industries and new industry agglomerations and supporting the development of new local economies, so as to promote economic restructuring, and strengthening the social solidarity and regional balance of the country through the implementation of largescale projects, the construction of transportation facilities and digital communication facilities, and the modernization of public service facilities, so as to promote the development of the area's difficulties and disadvantages.

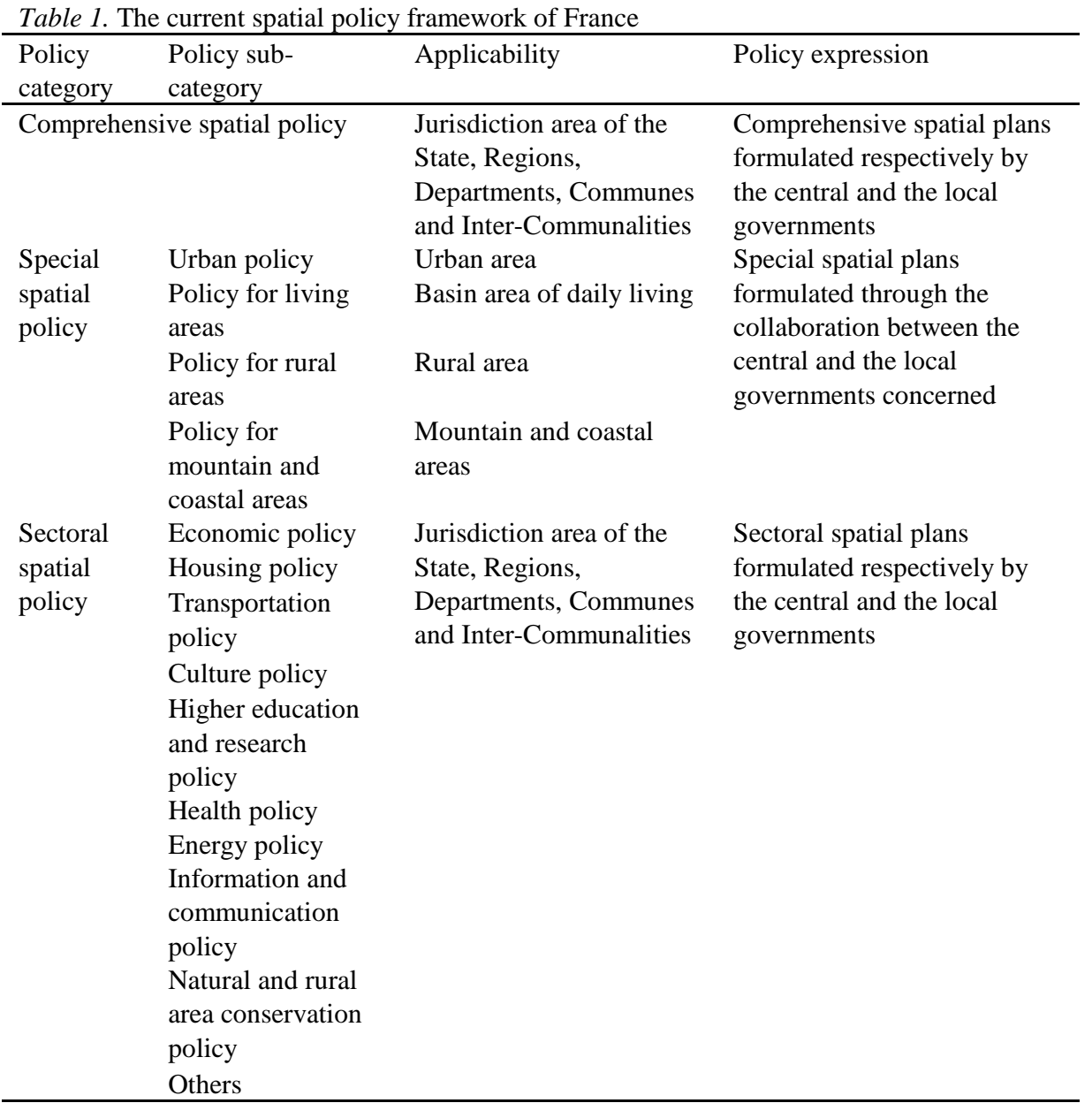




\subsection{Comprehensive spatial policy}

The comprehensive spatial policy refers to the comprehensive strategies of spatial development which are formulated respectively by the central and the local governments and are applicable to the corresponding jurisdiction areas. Being the main body of the French spatial policy framework, they concern the multiple aspects of society, economy, environment, culture, and urban construction, etc. and are elaborated through the comprehensive spatial plans of various levels.

Table 2. The comprehensive spatial policy expressed through the comprehensive spatial plans

\begin{tabular}{|c|c|c|c|c|}
\hline $\begin{array}{l}\text { Spatial } \\
\text { planning } \\
\text { system }\end{array}$ & $\begin{array}{l}\text { Title of spatial } \\
\text { Plan }\end{array}$ & Applicability & Organizer & $\begin{array}{l}\text { Planning } \\
\text { permit } \\
\text { management }\end{array}$ \\
\hline \multirow[t]{2}{*}{$\begin{array}{l}\text { National } \\
\text { planning }\end{array}$} & $\begin{array}{l}\text { National } \\
\text { Sustainable } \\
\text { Development } \\
\text { Plan (SNADT) }\end{array}$ & National territory & State & None \\
\hline & $\begin{array}{l}\text { Collective } \\
\text { Services } \\
\text { Blueprint (SSC) }\end{array}$ & & & \\
\hline $\begin{array}{l}\text { Regional } \\
\text { planning }\end{array}$ & $\begin{array}{l}\text { Regional Spatial } \\
\text { Planning and } \\
\text { Development } \\
\text { Blueprint } \\
\text { (SRADT) }\end{array}$ & $\begin{array}{l}\text { Jurisdiction area of } \\
\text { Regions }\end{array}$ & Region & None \\
\hline \multirow[t]{2}{*}{$\begin{array}{l}\text { Regional } \\
\text { urban } \\
\text { planning }\end{array}$} & $\begin{array}{l}\text { Spatial Planning } \\
\text { Directive (DTA) }\end{array}$ & $\begin{array}{l}\text { Jurisdiction area of } \\
\text { Regions and/or } \\
\text { Inter-Regional or } \\
\text { Inter-Departmental } \\
\text { Associations }\end{array}$ & $\begin{array}{l}\text { State or Region, } \\
\text { in collaboration } \\
\text { with the Regions } \\
\text { and/or } \\
\text { Departments } \\
\text { concerned }\end{array}$ & None \\
\hline & $\begin{array}{l}\text { Territorial } \\
\text { Cohesion } \\
\text { Blueprint (SCoT) }\end{array}$ & $\begin{array}{l}\text { Jurisdiction area of } \\
\text { Departments, Inter- } \\
\text { Departmental } \\
\text { Associations, or } \\
\text { Inter-Communalities }\end{array}$ & $\begin{array}{l}\text { Department, } \\
\text { Inter-Department } \\
\text { Association, or } \\
\text { Inter- } \\
\text { Communality }\end{array}$ & None \\
\hline \multirow[t]{3}{*}{$\begin{array}{l}\text { Local } \\
\text { urban } \\
\text { planning }\end{array}$} & $\begin{array}{l}\text { Local Urban } \\
\text { Planning Map } \\
(P L U)\end{array}$ & $\begin{array}{l}\text { Jurisdiction area of } \\
\text { Communes or Inter- } \\
\text { Communalities }\end{array}$ & $\begin{array}{l}\text { Commune or } \\
\text { Inter- } \\
\text { Communality }\end{array}$ & $\begin{array}{l}\text { Commune or } \\
\text { Inter- } \\
\text { Communalit } \\
\mathrm{y}\end{array}$ \\
\hline & $\begin{array}{l}\text { Communal } \\
\text { Map (CC) }\end{array}$ & $\begin{array}{l}\text { Jurisdiction area of } \\
\text { Communes }\end{array}$ & Commune & Commune \\
\hline & $\begin{array}{l}\text { National Urban } \\
\text { Planning } \\
\text { Regulations } \\
(R N U)\end{array}$ & $\begin{array}{l}\text { Jurisdiction area of } \\
\text { Communes without } \\
\text { either a Local Urban } \\
\text { Planning Map or a } \\
\text { Communal Map }\end{array}$ & State & State \\
\hline
\end{tabular}

Since the 2000s, these comprehensive spatial plans have included the National Sustainable Development Strategy (SNADT) or Collective Services Blueprint (SSC) at the national level, the Regional Spatial Planning and Development Blueprint (SRADT) at the Regional level, the Spatial Planning Directive (DTA) and the Territorial Cohesion Blueprint (SCoT) at the Inter-Regional, Inter-Departmental and/or Inter-Communal levels, and the Local Urban Planning Map (PLU), Communal Map (CC), and National 
Urban Planning Regulations (RNU) at the Communal and/or InterCommunal levels, all of which compose the main body of the French spatial planning system (Table 2). Although these plans are formulated by different territorial authorities, i.e. the State, Regions, Departments, Communes and Inter-Communalities, representing different interests and elaborating different objectives, they are all integrated into the unique spatial policy framework and spatial planning system, with the superior level plans being compulsory to the inferior level plans.

\subsection{Special spatial policy}

In some sense, the special spatial policy is a kind of comprehensive policy, but it concerns only four kinds of areas delimited according to specific statistical criteria. They are urban areas, living areas, rural areas, and mountain and coastal areas, with regard to which, the central government collaborates with the local governments concerned to work out special spatial plans in view of the local conditions and needs, which are then included in the contracts between the central and the local governments. The special spatial plans must accord with the comprehensive spatial plans of the superior levels, as well as those of the same level.

According to the definitions issued by the National Institution of Statistics and Economics Studies of France, an urban area (aire urbaine) refers to a group of Communes on a continuous territory without enclave which is composed of an urban center (pole urbain, the center of an urban unit (unite urbaine) which is a Commune or a group of Communes with a continuous built-up area, i.e. no more than 200 meters between two buildings, accommodating a population of no less than 2,000) offering more than 1,500 jobs, as well as a number of rural Communes (Communes rurale) belonging to no urban units, or urban units as suburban ring (couronne), where at least $40 \%$ of the local residents have a job in the urban center or in the Communes attracted by it (Institut National de la Statistique et des Études Économiques). A living area (bassin de vie) refers to the smallest scope where people have access to the most common equipment and services of personal services, commerce, education, health, sports, culture and leisure, and transportation (Institut National de la Statistique et des Études Économiques). and where urban, suburban and rural areas meet with each other, ignoring the administrative boundaries. The rural area refers to all the small urban units and rural Communes (commune rurale) that do not belong to any urban centers, suburban rings, and multi-centered Communes (commune multipolarisee), where no less than $40 \%$ of the local resident labor force working in several urban areas and which, together with these urban areas, form a continuous territory.

The special policy for urban areas concerns respectively the metropoles as engine of the national economy, the conurbations as agglomeration of urban Communes, the medium-sized cities as employment and service centre for rural areas, and the needy neighbourhoods in the above-mentioned urban areas. That for metropoles was firstly carried out in 2003 in the areas with a population over 500,000, except Paris Region, which includes at least one urban area of over 200,000 residents, in hope of strengthening the international competitiveness of the metropoles by promoting the internal cooperation and integration and the growth of new urban centres as well. That for conurbations was firstly applied in the late 1990s to the InterCommunalities that comprise several Communes forming a continuous territory, without enclave, and centred on a Departmental capital or one or 
more central Communes of more than 15,000 residents, with a population over 50,000, aimed at reducing the disparity and promoting the integration between the Communes through internal collaboration. That for mediumsized cities was implemented in 2006 in the urban areas with populations varying between 30,000 and 200,000, in order to revitalize the local economy by improving the accessibility to railways and aviation and the public services of education, culture and healthcare. That for the needy neighbourhoods in the above-mentioned urban areas was enforced since the early 1980s, for the sake of promoting the urban regeneration and social integration of the urban neighbourhoods' difficulties and disadvantages, due to socio-economic transition, by way of rehabilitating old houses, upgrading public services, and providing more job opportunities.

The special policy for living areas was put into effect in 2003 in the legally designated living areas, i.e. the areas where the residents share common geographical, cultural, economic or social interests within the same catchment area for work and leisure. Based on the long tradition of InterCommunal cooperation and the support of local civil societies, it is for the purpose of promoting the coordination among the Communes concerned and between the urban and rural areas, with a focus on the issues of public transportation, personal services for aging and kids, medical care service, and health care facilities, etc.

The special policy for rural areas classifies rural France into three categories, i.e. the rural areas' neighbouring cities, the new rural areas with tourism potentiality, and the traditional rural areas far from cities. It was carried out from 2005 for the purpose of maintaining the economic vitality, improving the living conditions, and protecting the natural environment of the rural areas through the implementation of a number of projects, such as Excellent Rural Centre (PER), Rural Revitalization Area (ZRR), and Regional Natural Park (PNR). As the three kinds of rural areas face different problems and challenges due to the differences in geographic location and socio-economic development, the policy tries to tackle them through different countermeasures, addressing challenges such as the conflict between real estate development and natural site protection for the rural areas' neighbouring cities, the weakened role of ecological protection due to the continuous inflow of migrants to new rural areas with tourism potentiality, and the dilemma of low revenue, decreasing population and stagnating economy for the traditional rural areas far from cities (Liu, 2010).

The special policy for mountain and coastal areas concerns the nine mountain areas of France, accounting for $29 \%$ of the national territory, and the littoral along the coastline of 7,200 kilometres. It was implemented in the 1980s with the objective of promoting ecological sustainability through limited urban development, diversified economic development, and integrated governance.

It should be noted that, as the four kinds of special areas are delimited according to statistical criteria, their scopes may change whenever a locality fails to meet the criteria. There is also the phenomena of one kind of area overlapping with other ones, especially between living areas and rural areas, which often results in confusion and difficulties in the implementation of special spatial policies.

\subsection{Sectoral spatial policy}

The sectoral spatial policy is an important complement to both the comprehensive and the special policies, which concerns the sectors of 
economy, housing, transportation, education, public services, and so on, in response to the actual needs of the socio-economic development. It is expressed through a series of sectoral plans which are formulated either by the central and the local governments respectively or through the collaboration between them, within the scope of their respective authorities, and are applicable to the corresponding jurisdiction areas.

For example, as higher education is an authority of the central government, the sectoral plan for higher education development is formulated by the central government and applicable to the whole country. As economic development is the authority of the local governments at all levels, but with different focuses one from another, the sectoral plans for economic development are formulated respectively by the local governments at various levels and applicable to the corresponding jurisdiction areas. For the economic development of any of the four special areas, such as the rural areas, the sectoral plan is then formulated through the collaboration between the central and the local governments concerned and applicable to the specific areas concerned. However, no matter who is in charge and what are the contents of the plans, the sectoral plans must accord with the comprehensive plans of both the superior and the same levels, as well as the sectoral plans of the superior levels.

\section{SPATIAL PLANNING SYSTEM}

As carrier of comprehensive spatial policies, the comprehensive spatial plans constitute the main body of the French spatial planning system which is an hierarchical system including SSC as the national plan, SRADT as the regional plan (Regional), DTA and SCoT as strategic urban plan at the regional level (Inter-Regional, Inter-Departmental, Departmental and InterCommunal), PLU, CC and RNU as regulatory urban plan at the local level (Inter-Communal and Communal) (Table 2), and the Plan of Protection and Enhancement (SPMV) and the Plan of Concerted Development Zone (PAZ) as operational urban plan at the neighbourhood level (Secrétariat Général du Gouvernement, 2018). All these plans are formulated respectively by the central and the local governments and play the role of guiding the actions and practice of spatial development taking place on the corresponding territories. Among them, the national plans, Regional plans and regionallevel urban plans play the role of strategic guidance, while the local urban plans, i.e. the regulatory and operational urban plans, have a normative effect. All the superior level plans are compulsory to the inferior level plans while all the inferior level plans should respect the regulations of the superior plans.

\subsection{SSC as strategic national plan}

SSC was instituted by the Voynet Act of 25 June 1999 to play the role of national plan in place of SNADT which was instituted by the Pasqua Act of 4 February 1995, but never formulated under the circumstance of administrative decentralization. It refers to a series of reference planning documents concerning the collective services of higher education and research, culture, health, information and communication, transport, energy, natural and rural space and sport, all of which are thought strategic for the sustainable development of the country. Being a sectoral spatial plan covering the whole national territory, these planning documents are 
formulated by the central government for the purpose of assuring the strategic role of the State in spatial development and facilitating the formulation of SRADT which shapes the contents of the contract between the State and the Regions over a long-term period of 20 years. They are approved by a decree of the State Council after consultation at the Regional scales.

\subsection{SRADT as strategic regional plan}

SRADT was instituted by the Pasqua Act of 4 February 1995 which later on, as sustainable development became a primary concern in French society, was renamed the Regional spatial Planning and Sustainable Development Blueprint (SRADDT). After France restructured the administrative division of Regions in 2016, SRADDT was required to be integrated with other sectoral plans at the Regional level, into the Regional Spatial Planning, Sustainable Development and Equity Blueprint (SRADDET).

SRADT was formulated by the Regional government, in collaboration with certain local governments and Inter-Communalities, Regional Natural Parks, living areas, and civil societies, and approved by the Regional Council. Being a comprehensive spatial plan for a Region without normative effect, it is meant to set up the guidelines for the Region's sustainable development over a long-term period of 20 years and to shape the contents of the contract between the State and the Region concerned, with respect to SSC. It deals with the issues of the location of major facilities, infrastructure and services of general interest, the development of economic projects, the harmonious development of urban, suburban and rural areas, the protection and conservation of environment, landscape and natural heritage, the rehabilitation of derelict areas, the incorporation of Inter-Regional or crossborder planning, and the infrastructure program and the organization of regional transportation, more specifically, rail transport.

\subsection{DTA and SCoT as strategic urban plan at the regional level}

DTA, renamed as Spatial Planning and Sustainable Development Directive (DTADD) according to the Grenelle II Act of 12 July 2016 to show the considerations on environment, targets the specific areas with strategic significance, including those where it is hard to lay out major transportation infrastructure and social service facilities due to geographical constrains, as well as those that are facing demographic pressures, land shortage, and ecological risks, such as the coastal areas, mountain areas and urban peripheries. It aims at strengthening the coherence and coordination of various national spatial policies concerning the above-mentioned areas, controlling the actions of local governments in spatial development, and specifying the special spatial policy for mountain and coastal areas, so as to balance development and preservation and to maintain social mix and urban diversity. It sets out from the national or regional perspective the objectives of governing and balancing the development, preservation and utilization of territory, as well as the principles for laying out large-scale transportation infrastructure and public service facilities and preserving natural spaces and historic sites. The formulation of DTA is at the initiative of either the State or the Region and is conducted by the central government in association with the local authorities concerned, including Regions, Departments, 
Communes and Inter-Communalities. Thus, the formulation itself is a process of negotiation for common views among the stakeholders, which favours a partnership among them. It is approved by a decree of the State Council after a consultation with the Inter-Ministry Committee of Spatial Planning and Development (CIADT) and is compulsory to SCoT and inferior level urban plans.

Transformed from the Master Plan of Spatial and Urban Development (SDAU) instituted in the 1960s, SCoT was instituted by the Urban Solidarity and Renewal Act of 13 December 2000 (SUR) for the purpose of coordinating the sectoral policies relating to urban planning, housing, transportation and commercial facilities. Targeting the specific area of conurbations on a continuous territory without enclave, it is formulated by either the Departmental government or the Inter-Communality concerned, following the principles of balanced development, urban renovation, land use efficiency, social mix and environmental preservation. It sets out the general guidelines of spatial planning over the long-term to maintain a balance between the built-up, natural, farming or forest areas, as well as the objectives for balancing housing, social mix, public transport, and commercial and business facilities. In line with the SRDAT concerned, as well as the DTA concerned in case of existence, it is based on a Spatial Planning and Sustainable Development Proposal to show due considerations on environment. It is reviewed every ten years to ensure its actual efficiency.

\subsection{PLU, CC and RNU as regulatory urban plan at the local level}

Both PLU (including PLUI for Inter-Communalities) and CC are instituted by the Urban Solidarity and Renewal Act of 13 December 2000, replacing the previous regulatory urban plan, Land Use Plan (POS). They target large- and medium-sized Communes / Inter-Communalities respectively and are formulated by the Communal / Inter-Communal governments for purpose of zoning the Commune / Inter-Communality into four areas, i.e. general urban area, urban facility area, urban green area, and natural and forestry area, and set out the planning regulations of building and land-use, as the basis for urban planning management. They are also based on a Spatial Planning and Sustainable Development Proposal to show due considerations on environment.

As the French administrative division system is characterized by a large number of small Communes, there are always the Communes / InterCommunalities that are not able to formulate even a CC due to various reasons, such as the lack of technical force, the insufficiency of financial support or the too small scale of population. In these cases, the RNU formulated by the agencies of the central government will take place of CC as the regulatory urban plan. Following the principle of limited construction, that is to prohibit any new constructions outside any actual urbanized areas, it aims at restraining disordered urban sprawl and protecting natural spaces and landscape. Taking into consideration the actual situation of existing constructions and their relationship with the surrounding environment, it delineates the actual urbanized areas and sets out the planning regulations of building and land-use on the commonly agreed constructible lands. 


\subsection{PSMV and PAZ as operational urban plans at the local level}

Targeting historic neighbourhoods and urban renovation or new development areas respectively, PSMV and PAZ are formulated and approved by the local government of Communes / Inter-Communalities, for the purpose of defining the planning and design of the construction projects on the territory concerned, so as to regulate the actions of construction and development. In the case that an urban renovation or new development project is nominated as an Operation of National Interest (OIN), the PAZ can also be formulated by the agencies of the central government (Liu, 2013a, 2013b).

\section{IMPLEMENTATION OF SPATIAL POLICIES AND SPATIAL PLANS}

As French spatial policies are embodied in a series of comprehensive, special and sectoral spatial plans that involve the multiple territorial levels of State, Region, Department, Commune, and Inter-Communality, the specific areas crossing the administrative borders of Regions, Departments, Communes and Inter-Communalities, and the multiple aspects of economy, transportation, culture, education, and so on, the implementation of these spatial policies and plans is inevitably a participatory process by all the central and the local governments, as well as their departments concerned. This process can be simplified as "one region, one strategy and one contract", with "one region" referring to the jurisdiction area of a certain authority to which specific spatial policies and plans are to be applied, "one strategy" referring to the spatial policies and plans to be implemented, and "one contract" referring to the cooperation contract between the central and the local governments to implement the specific spatial policies and plans. In detail, for the spatial development of a certain area, the central and the local governments, as well as their departments concerned, should formulate respectively the spatial plans within their respective authority and take their responsibility to implement the spatial plans respectively within the framework of a cooperation contract between them. In France, the contractual approach of inter-governmental cooperation was established in the 1960s and 1970s, for the purpose of promoting cooperation between the central and the local governments in the field of spatial development, by specifying the goals, actions and financial terms of the spatial development projects which they will respectively or jointly implement.

\subsection{Planning Contract between Central and Regional Governments}

The Planning Contract between Central and Regional Government was instituted by the Act of 29 July 1982 as part of the regional planning process. It outlines the strategic priorities for a Region which are a focal point for discussions between the central and Regional governments. Based on the discussions, the two parties agree on an action plan of spatial development in the Region, covering the subjects of major infrastructure for transportation or higher education, regional industry or agriculture, and research, health, culture, etc., as well as the financing program for the 
actions. The contract consists of three sections, dealing with the Regional, the local, and the Inter-Regional projects respectively.

In 2006, based on a series of consultations, the contractual approach was transformed into the Project Contract between Central and Regional Government, focusing mainly on three priorities. The first is local competitiveness and attractiveness, with support to competitive industrial clusters, research and higher education, urban facility construction, agricultural development, and transport network upgrading and expansion, excluding the expressways and rail transport. The second is the environmental dimension of sustainable development, including the fight against climate change, the comprehensive and balanced management of water resources, the increasing awareness of natural and technological risks, and the maintenance and enhancement of biodiversity. The third is social and spatial integration, concerning employment and vocation training, economic change, urban renewal, and the specific problems of overseas Departments and mountain areas.

\subsection{Local Project Contract}

As one of the three sections of the Planning Contract between Central and Regional Government, the Local Project Contract is applicable to certain areas within a Region, such as conurbations, living areas, and Regional Natural Parks, regarding which the localities concerned can sign a contract with the central government and the Regional or Departmental government, within the framework of the Planning Contract between Central and Regional Government, on the implementation of the spatial development projects of transportation, education, economy, urbanization, urban renewal, and so on. The existing Local Project Contracts mainly deal with the sustainable development policies for conurbations, the construction of local digital networks to enhance economic competitiveness, the local strategies for coping with climate change, the prevention of natural risks, the adaptation of public services, and the initiation of innovative personal services, etc.

\subsection{Diversity of Contracts}

In practice, the contractual approach is quite flexible and diverse, leading to the coexistence of different types of contracts. Each Regional or Departmental government can implement one or more types of contracts relating to specific areas within the Region or Department. The central government can sign a wide range of contracts besides the Planning Contract between Central and Regional Government and the Local Project Contract, for example, the site contracts introduced in 2003, such as City Contract and Urban Social Cohesion Contract, to help the areas struggling with industrial restructuring to revive the economy and create new jobs, and the contracts with large state-owned enterprises, such as the Post Office of France, Electricity of France (EDF), and Gas of France (GDF), to set out the objectives of spatial development for these enterprises. 


\section{CONCLUSIONS}

The above descriptions and analyses demonstrate that the French spatial policy framework and spatial planning system constitute a mechanism of coordinating various spatial plans formulated by different stakeholders at different levels through an integral spatial planning system based on an integral spatial policy framework, which shows the effects of balancing regional development and urban-rural development, implementing special management over specific areas, encouraging cooperation among various governments and departments, and integrating implementation through urban plans, with the central government playing an active role.

\subsection{Balancing Regional and Urban-Rural Development}

Although in France, like in other countries, there are criteria distinguishing urban areas from rural areas, it is only a statistical representation of the two kinds of areas having different socio-economic characteristics. The administrative division system, which takes Commune as the basic administrative unit, implies no distinction among cities, towns and villages, no matter how different they are in terms of population size, functional role and development level. The comprehensive spatial policies and spatial plans are implemented at the multiple territorial levels of State, Region, Department, Commune and Inter-Communality respectively, involving both urban and rural areas, as well as developed and developing areas. This helps promote balanced development not only between urban and rural areas but also among different regions.

\subsection{Implementing Special Management over Specific} Areas

Nevertheless, balancing regional and urban-rural development does not mean to equally implement the same spatial policies and spatial plans to all the territories, regardless the actual differences between them in terms of society, economy, environment, and culture, etc. In contrast, the French spatial policy framework and spatial planning system place great emphasis on the regional and urban-rural disparities. Regarding certain areas of special significance in terms of society, economy and environment, special policies are formulated at different levels and in different sectors, as complement to and extension of comprehensive policies. In this way, while the comprehensive policies promote balanced regional and urban-rural development at different levels, the special policies ensure to meet the special demands of specific areas, which is necessary for a balanced spatial development on the whole national territory.

\subsection{Encouraging Cooperation between Governments and Departments}

The contractual approach, represented by different types of contracts, sets up a mechanism of cooperation between the governments of various levels, as well as their departments, ensuring that each takes its due responsibility of implementing the spatial policies and spatial plans regarding a specific area, based on mutual agreement and within respective authority. Under the circumstance of administrative decentralization, it 
guarantees the authority of the central government in spatial development and planning to achieve the goal of balanced spatial development over the whole country, while respecting and meeting the specific demands of the localities.

\subsection{Presenting Integration in Urban Plans}

The French spatial planning system prescribes that regional planning is compulsory to urban planning and superior level urban planning is compulsory to inferior level urban planning. This makes the local urban planning at the bottom of the spatial planning system become the ultimate embodiment of all the superior level spatial policies and the ultimate collection of all the superior level spatial plans (Figure 1). Being a kind of regulatory spatial plan regarding a Commune or an Inter-Communality, it concretizes the spatial development projects, proposed by the superior level spatial plans according to the spatial policies of the superior level governments, in the regulations of land use and spatial layout, so as to ensure the integration and the realization of the superior level spatial policies and plans.

\subsection{Active Role of Central Government}

According to the Constitution Amendment Act of 2003 and as result of the administrative decentralization since the 1980s, the local governments of France are endowed with different authorities and powers and they operate independently following the principles of free administration, no oversight of one over another, financial autonomy, and central government supervision after the fact. This institution gives the local governments full autonomy of spatial planning within the scope of their respective authority. In spite of that, the central government still retains the right of direct or indirect intervention on the local spatial development and planning through top-level design and plays an active role in spatial policy-making and spatial planning, so as to guarantee a comprehensive and well-balanced spatial development across the country. For example, on the one hand, it may prescribe the powers and responsibilities of spatial development and planning of the local governments by structuring the spatial planning system, issue spatial policies to show the national orientations on spatial development and planning, and set up contracts with the local governments to join the implementation of spatial plans; on the other hand, it may formulate DTA in collaboration with the local governments concerned for some strategic areas, such as socially and ecologically vulnerable areas, formulate regulatory urban plans for the Communes or Inter-Communalities that are incapable of accomplishing the mission, and formulate operational urban plans and conduct planning permission management for the major development areas which are significant to the national economy and people's livelihoods, especially those representing national competitiveness. 


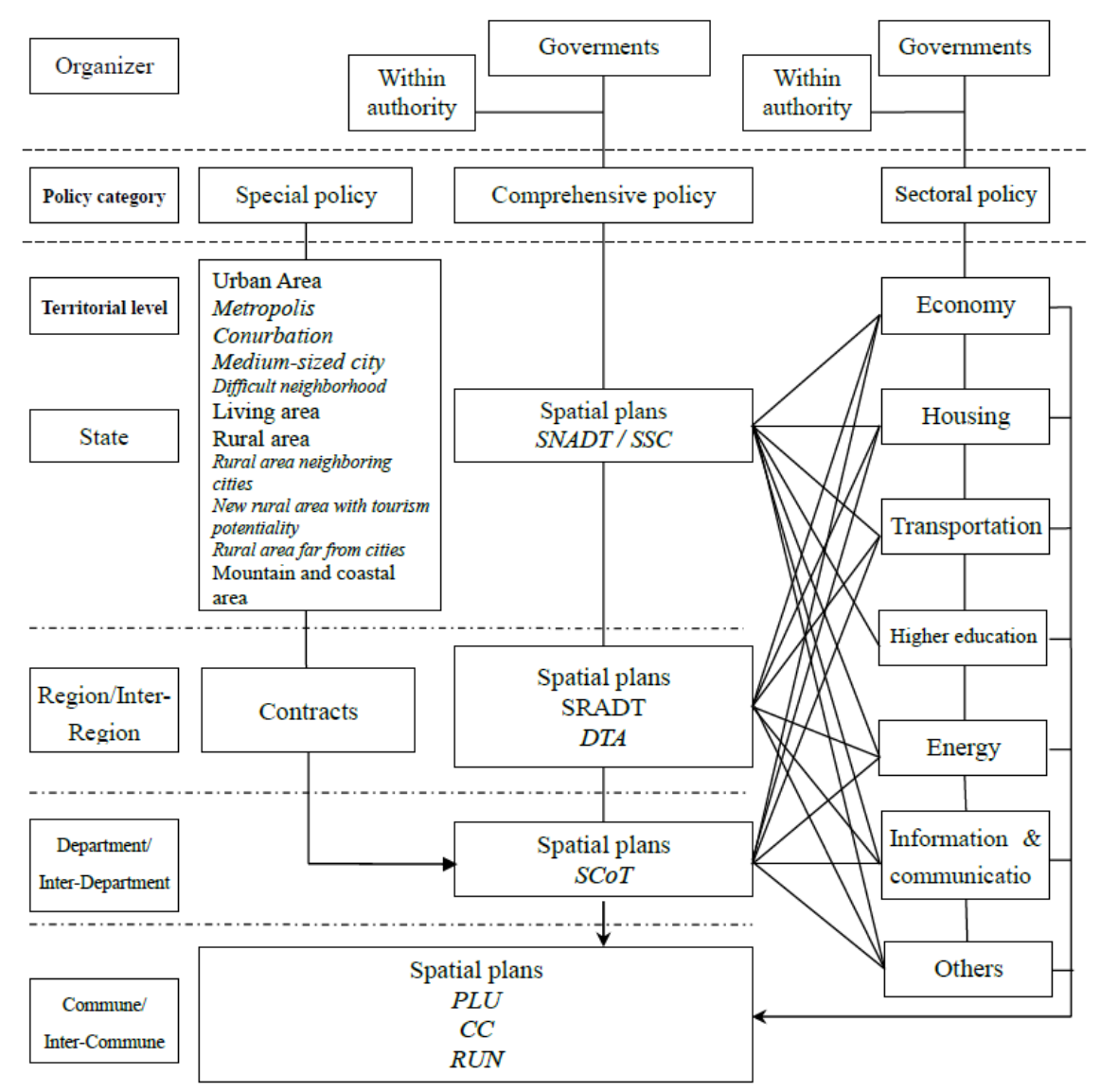

Figure 1. Interrelation between spatial policies and spatial plans in France

\section{REFERENCES}

Bertrand, F. (2005). "Aménagement du territoire et développement durable", La documentation française.

Ecrement, B. (2002). "Urbanisme, habitat, déplacement: l'expérience de la France (19502000)", Texte Disponible En Ligne Sur Le Site Du Centre de Documentation de l'urbanisme.

Gambino, M. (2010). "Politique d'Aménagement du Territoire, Agriculture Energie 2030", Ministère de l'Agriculture, de l'Alimentation, de la Pêche, de la Ruralité et de l’Aménagement du Territoire, Centre d'Etudes et de Prospective-Service de la Statistique et de la Prospective.

Geppert, A. (2015). "Planning without a spatial development perspective? The French case", Planning for States and Nation/States: A TransAtlantic Exploration. 381-410.

Huang, Y. (2012). "Institutional reform and plan integration: Observation and thinking of domestic Three Plans’ Integration", Modern Urban Research, 27(2), 10-14. Retrieved from http://en.cnki.com.cn/Article_en/CJFDTotal-XDCS201202005.htm

Institut National de la Statistique et des Études Économiques (INSEE). https://www.insee.fr/fr/metadonnees/definition

Lai, S., Huang, H., Chen, J., \& Chen, X. (2013). "From technical innovation to institutional innovation: Three-Plan-Coordination practice in Heyuan, Yunfu and Guangzhou", Urban Planning Forum, 210(5), 63-68. Retrieved from http://en.cnki.com.cn/Article_en/CJFDTotal-CXGH201305009.htm

Liu, J. (2010). "Rural development and its planning management in France: An experience in line with the principle of balanced urban-rural development", Urban Planning International, 25(2), 4-10.

Liu, J. (2011). "Policy framework and planning system of territorial development in France: Characteristics and inspirations", City Planning Review, 35(8), 60-65. Retrieved from http://en.cnki.com.cn/Article_en/CJFDTOTAL-CSGH201108015.htm 
Liu, J. (2013a). "Practice of historic preservation in France: A case study on Paris", Beijing Planning \& Construction, 27(3), 22-28.

Liu, J. (2013b). "Urban renovation through holistic creation in France: The planning mechanism of ZAC and its implementation in Paris", Urban Planning International, 28(6), 57-66.

Luo, Y., \& Mao, D. (2015). "Progress on study about planning coordination and merge in China", Journal of Urban Studies, 36(2), 77-81. Retrieved from http://en.cnki.com.cn/Article_en/CJFDTotal-YYSZ201502015.htm

Merlin, P., \& Choay, F. (1988). "Dictionnaire de l'urbanisme et de l'aménagement",.

Ministère des Affaires étrangères, D. générale de la C. internationale et du D. (2006). "Spatial Planning \& Sustainable Development Policy in France", Mediatys / Groupe Corlet, Paris.

Secrétariat Général du Gouvernement (SGG). (2018). "Code de l’Urbanisme". Retrieved from https://www.legifrance.gouv.fr/affichCode.do?cidTexte=LEGITEXT000006074075

Xie, Y., \& Wang, W. (2015). "From multiple-plan coordination to the reform of the spatial planning system", Urban Planning Forum, 223(3), 15-21. Retrieved from http://en.cnki.com.cn/Article_en/CJFDTotal-CXGH201503003.htm

Yang, D. (2016). "Reconstructuring sustainable spatial planning system: Innovation and relevant debates of the UK government since 2010", City Planning Review, 40(8), 91-99. Retrieved from http://en.cnki.com.cn/Article_en/CJFDTotal-CSGH201608018.htm

Zhang, S., Feng, C., \& Liu, C. (2014). "Progress of Dutch Spatial Planning System", Urban Planning International, 29(5), 89-94. Retrieved from http://www.upiplanning.org/EN/Magazine/Show.aspx?ID=45434

Zhang, Z., \& Huang, D. (2007). "The enlightenment of German experience of spatial planning system reform to the Chinese counterparts", Modern Urban Research, 22(6), 11-18. Retrieved from http://en.oversea.cnki.net/kcms/detail/detail.aspx?QueryID=16\&CurRec=1\&dbCode=CJF D\&filename $=$ XDCS200706002\&dbname $=$ CJFD2007

Zhou, J., Hu, T., \& Gu, Y. (2017). "National spatial planning and coordination system in the Netherlands", Planners, 33(2), 35-41.

Zhou, S., Zhai, G., \& Shi, Y. (2017). "Spatial Planning Experience in England and Its Implications to China", Urban Planning International, 32(4), 82-89. https://doi.org/10.22217/upi.2016.520

Zhou, Y., Pu, L., \& Zhang, F. (2006). "Spatial planning in Germany with its implication in China", Resources and Environment in the Yangtze Basin, 15(4), 409-414. Retrieved from http://caod.oriprobe.com/articles/10865221/SPATIAL_PLANNING_IN_GERMANY_WI TH_ITS_IMPLICATION_IN_CHINA.htm

Zhu, J., Deng, M., \& Pan, A. (2015). "Three planning in one: Exploring the order and regulation capacity of spatial planning", City Planning Review, 39(1), 41-47/97. Retrieved from http://en.cnki.com.cn/Article_en/CJFDTotal-CSGH201501009.htm

Zhuo, J., \& Liu, Y. (2004). "Urban planning decentralization policy in France: A brief review on the evolution of urban planning system in France from 1919 to 2000", Urban Planning International, 19(5), 7-16. Retrieved from http://www.upiplanning.org/EN/Magazine/Show.aspx?ID=43966 